\title{
ESPERANZA, SALUD Y BIENESTAR
}

\section{Hope, health and wealth}

Mario Pereyra Lavandina*

\section{Resumen}

El autor realiza una reseña de las investigaciones más importantes realizadas con pacientes (y no pacientes) de diferentes áreas de la salud y como influyen la disposición optimista o pesimista que experimentan en su estado físico. En todas estas aportaciones se descubren informaciones sorprendentes y funciones insospechadas que coinciden en exhibir a la esperanza como un verdadero "laboratorio de la salud".

Palabras clave: Psicología positiva, esperanza, salud.

\begin{abstract}
The author overviews the most important researches made on patients (and non-patients too), from different health care areas, to identify the influence that the patients'optimism or pessimism may have on their physical condition. These contributions provided amazing information and unsuspected functions, wherein it is agreed that to have hope is the true "laboratory of health".
\end{abstract} Key words: Positive psychology, hope, health.

* Universidad de Montemorelos, Nuevo León, México 


\section{LA MEDICINA DE LA ESPERANZA}

"La esperanza es la medicina milagrosa de la mente. Ella inspira la voluntad de vivir. Ella es un poderoso aliado. W. Peterson (1961)

El Profesor Fred O. Henker (1985), de la Universidad de Arkansas, relata el caso de una paciente de 49 años, casada y madre de dos adolescentes. Había recibido una implantación de válvula mitral a los 47 años, evolucionando normalmente durante un año. Luego empezó a mostrar signos crecientes de descompensación cardiaca. Se decidió hacer un nuevo reemplazo. Cuando estaba internada para la cirugía dio muestras evidentes de pesimismo. Sus hijos eran indiferentes con ella y le hacían sentir que estaba de más. Su esposo se ponía cada vez más impaciente. La mujer hizo algunos comentarios reveladores: "esto no va a servir para nada", "tengo la sensación de que no voy a pasar este trance", "estoy pronta para irme". La operación fue un éxito. Se tomaron todas las precauciones para una buena alta. Sin embargo, al segundo día del postoperatorio tuvo una falla cardiaca y murió. Todos los recursos estaban a disposición y fueron utilizados, excepto uno -termina diciendo Henker- "la esperanza de parte del paciente".

¿Cómo se desarrolla y crece la esperanza? ¿De qué manera se puede acrecentar y fortificar para que constituya un motor generador de salud y de plenitud de vida? Hay quienes tienen una actitud temerosa o de falta de osadía ante el futuro que los incapacitan para triunfar. Como esperan muy poco o no esperan nada, nada consiguen y sufren en el alma y el cuerpo esa falta de vuelo.

Quizás un ejemplo ilustrativo que habla del poder de la esperanza sea la experiencia de Joan, una estudiante que se recuperó de la anorexia, según le relató a su profesora S.L. Moore (2005, 101-102), de la Universidad de Athabasca en Canadá.

"A lo largo de mi enfermedad llegué a perder el sentido de la esperanza. Había renunciado a toda esperanza de recuperación. Caí en un pozo profundo de depresión y desesperación, lleno de negrura y dolor. No veía ninguna luz ni camino, sólo la oscuridad en que me encontraba. Sin embargo, a pesar de mi estado, mi madre me dio la esperanza para seguir adelante y luchar por mi vida. Ella me enseñó que aun en las circunstancias más desesperantes y terribles siempre hay esperanza. 'Eso es, precisamente, lo que debes encontrar.' Tú puedes recuperar la esperanza en lugares impensados, de personas que no esperabas o a través de eventos que nunca habías imaginado. Antes de que la muerte me tomara, pude darme cuenta que existía la esperanza. Aún en la más profunda adversidad hay lugar para la esperanza si tienes la voluntad para buscarla."

En un sentido general, podemos asegurar con el filósofo alemán Ernst Bloch (1980), que la esperanza es un Laboratorium possibilis salutis, un "laboratorio posible de salud". Las investigaciones han demostrado de manera incuestionable y con una infinidad de evidencias experimentales, que "la dinámica de la esperanza está profundamente conectada con la esencia de la vida humana, el bienestar y la salud" en quienes sufren una enfermedad, como por ejemplo, el SIDA (Kylma, 2005). También se ha encontrado correlaciones altamente significativas entre la desesperanza, el sufrimiento y la enfermedad, especialmente en los estados depresivos (v.gr., Srikumar et al., 2000; Morris et al., 2005) y en los actos suicidas (Cassells et al., 2005).

Probablemente entre los estudios más demostrativos se encuentren las investigaciones de seguimiento de miles de personas examinadas en su estado de salud y en sus niveles de esperanza durante períodos prolongados. Uno de ellos (Anda et al., 1993), fue desarrollado por el departamento de Salud Nacional de Estados Unidos (US Nacional Health), que evaluaron 2832 personas durante más de 12 años, encontrando que los desesperanzados tenían un riesgo muy alto de contraer una enfermedad fatal del corazón en comparación con quienes reportaban altos puntajes de esperanza. En otro estudio, realizado en Finlandia, sobre 2428 hombres, seguidos durante 6 años, también se encontró que la mortalidad debido al cáncer era muchísimo mayor en los desesperanzados (Everson et al., 1996), que en el grupo de control. Finalmente, en San Antonio, Texas, Stern y colaboradores (2001), exploraron a casi 800 personas de origen mexicano y europeo, entre 64 y 79 años, para descubrir que 5 años después, el $29 \%$ de los 
desesperanzados habían fallecido en comparación con el $11 \%$ de los esperanzados, lo que significa que los desesperanzados tienen casi tres veces más posibilidad de morir anticipadamente en comparación con los esperanzados.

Todas estas consideraciones permite sostener que la visión esperanzada o desesperanzada que pueda asumir una persona, grupo o comunidad es facilitadora de los procesos de salud o de enfermedad, ya que influye en forma decisiva en la restauración, el mantenimiento como en la promoción de la salud física (Kylma, 2005) y mental (Viñas et al., 2004). Por eso ha sido considerada como un ingrediente esencial para el ser humano, tanto como "la comida y el agua" (Fitzgerald, 1979) o "tan necesaria como el aire" para vivir (Tiger, 1979, 13). Así, pues, resulta forzoso reconocer que es la "esperanza lo que marca la diferencia", como asegura la Dra. Sharon Moore (2005), tanto en la salud como en la enfermedad. Por lo tanto, en el corazón de la práctica clínica de todos los agentes de salud, la estrategia fundamental de la atención de los médicos, psicólogos, enfermeras (Moore, 2005, 100), como de los trabajadores sociales (Itzhaky et al., 2004) y todo aquel que busque ayudar a su prójimo, debiera ser inspirar y fomentar la esperanza de sus pacientes como de todos aquellos con quienes nos relacionamos para incrementar el bienestar personal y social.

Para fortalecer estas primeras apreciaciones y precisar las operaciones de la esperanza, haremos una reseña de las investigaciones más importantes realizadas con pacientes (y no pacientes) de diferentes áreas de la salud y como influyen la disposición optimista o pesimista que experimentan en su estado físico. En todas estas aportaciones se descubren informaciones sorprendentes y funciones insospechadas que coinciden en exhibir a la esperanza como un verdadero "laboratorio de la salud".

\section{ESPERANZA EN LA FERTILIDAD Y EL EMBA- RAZO}

"La esperanza es el principal recurso humano para soportar el estrés."

A.O. Obayuwana et al. (1984)

La esperanza tiene una acción notable sobre el sistema endocrinológico. Debora Lancastle y Jacky Boivin de la Universidad de Cardiff, del país de Gales (2005), estudiaron a 97 mujeres, que tenían un promedio de edad de 33 años, que realizaron un tratamiento para tener un hijo. Buscaban ayudar a las parejas con problemas para lograr el embarazo, con intervenciones farmacológicas (por ej., hormonas) y físicas. Durante el desarrollo normal del ciclo menstrual la glándula pituitaria libera dos hormonas, la luteína (LH) y el folículo estimulante (FSH). Estas hormonas estimulan el crecimiento de 15 a 20 folículos que contienen los ovocitos. Cuando el ovocito madura, el ovario segrega estrógeno, el cual retroalimenta la pituitaria que hace decrecer la producción de FSH, permitiendo que solo un folículo madure. Cuando los niveles de estrógeno o estradiol permanecen altos se maximiza el número de ovocitos que pueden ser recuperados para la fecundación in vitro. En síntesis, los niveles de estradiol, el número de folículos y de ovocitos son componentes esenciales de la función reproductiva femenina. En esta investigación evaluaron estas tres variables biológicas conjuntamente con tres factores psicológicos, que fueron el nivel de ansiedad, la actitud de afrontar las dificultades por la vía de la evasión y la disposición optimista o esperanzada de las mujeres indagadas. Tres meses antes de iniciar el tratamiento de fertilización se realizó una entrevista con cada una de las mujeres que aplicaron para realizar la investigación y les realizaron las pruebas psicológicas. Durante el tratamiento de fertilización se evaluaron las variables biológicas.

Los resultados encontraron diferencias estadísticas significativas entre las variables psicológicas entre sí y las biológicas entre sí, pero además se verificó que las variables psicológicas predicen los resultados de las respuestas biológicas al tratamiento de la fertilidad $\left(\_=-.36, \mathrm{p}<. .05\right)$, como se aprecia en la figura 1. 


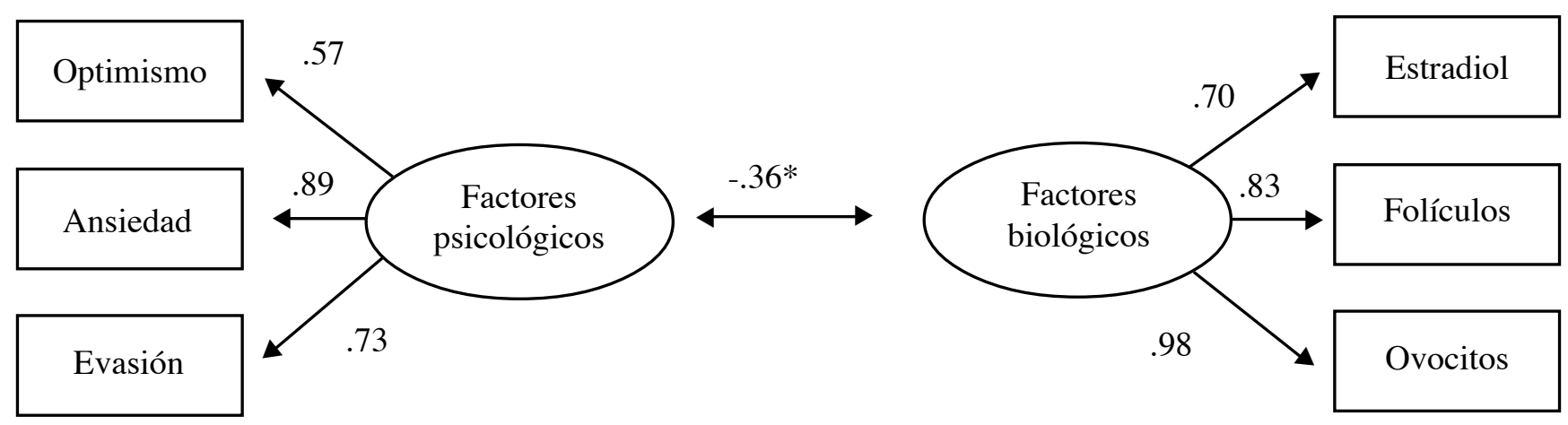

Figura 1. Modelo de ecuación estructural que prueba el complejo de variables psicológicas como predictoras de la respuesta biológica en el tratamiento de fertilización (Lancastle y Boivin, 2005)

Otra notable investigación fue realizada por Alphonsus O. Obayuwana y su equipo (1984), del Instituto de la Esperanza de Maryland, USA, sobre mujeres embarazadas. Durante tres años estuvieron evaluando las mujeres grávidas que llegaban al servicio, hasta completar una muestra de 185 mujeres. Al concurrir a la primera visita de control ginecológico les aplicaron una prueba de medición de la esperanza, The Hope Index Scale-HIS (Obayuwana et al., 1982) para determinar el grado de esperanza. Según el puntaje obtenido las clasificaron en dos grupos: las esperanzadas -las de mayor puntaje en el HIS- y las desesperanzadas -las de menor puntaje-. Luego examinaron el desempeño que tuvieron durante el parto. Consideraron todos los parámetros posibles referentes a las condiciones de la madre y del bebé en el momento del nacimiento.

Los resultados fueron espectaculares. Todas las madres de alto nivel de esperanza lograron los puntajes más bajos de morbilidad neonatal y maternal, es decir, tuvieron partos normales (sin cesárea) y niños sanos. En cambio las mujeres con bajo puntaje de esperanza (fueron 16 las desesperanzadas), el 80\% tuvo algún tipo de complicación, como ser, una mayor estancia en el hospital, infecciones, cesárea, atrasos o adelantos considerables en el parto, depresión post-parto e incluso hubo un caso de muerte en útero. El Dr. Obayuwana concluye asegurando enfáticamente que la esperanza, "es el principal recurso humano para soportar el estrés" haciendo al organismo menos vulnerable a las situaciones de riesgo.
Estos resultados tan llamativos en embarazadas fueron verificados por otros estudios posteriores. Así, por ejemplo, Cutrona (1982), investigó las causas de la depresión post-parto sugiriendo la importancia de la esperanza y el optimismo como disposición preventiva para impedirla. Posteriormente el tema fue abordado por Carver y Gaines (1987), quienes descubrieron que efectivamente el optimismo estaba asociado con la resistencia para sufrir una depresión post-parto. Estos autores puntualizaron dos hallazgos importantes:

1) Que el optimismo contrarresta la depresión; y

2) Que el optimismo parece ser una función amortiguadora del estrés y de sus efectos adversos.

Por último, es importante destacar el estudio de Marci Lobel y su equipo (2000), que examinaron el impacto del estrés y la disposición optimista sobre las madres y sus bebés en el momento del alumbramiento. Evaluaron una muestra de 129 madres en sus niveles de estrés prenatal y el grado de optimismo. Los resultados volvieron a confirmar la hipótesis de que las optimistas presentaron partos normales con hijos sin ningún problemas, en tanto, las pesimistas procrearon hijos con un peso significativamente menor que el promedio, entre otras complicaciones. 


\section{LA ESPERANZA EN EL AFRONTAMIENTO DE UNA CIRUGÍA}

"Nunca una noche ha vencido al amanecer, y nunca un problema ha vencido a la esperanza." Bern Williams

Ya en la primera mitad del siglo pasado, Deutsch (1942) señaló el papel central que desempeña la ansiedad en la fase preoperatoria y el miedo al daño físico y la pérdida de la vida. En ese sentido decía que una forma sana de enfrentar el miedo a la muerte era tener una "relación positiva con respecto a la vida". Por su parte, Abram y Gill (1961), informaron que la excesiva ansiedad preoperatoria, el adoptar una actitud negadora y tener expectativas poco realistas (falsa esperanza), son predictores bastante confiables de complicaciones psiquiátricas posoperatorias. Caplan y Hackett (1963, 1966), observaron en amputaciones de una extremidad inferior, que una reacción depresiva omnipresente después de la operación eran los "sentimientos de desesperanza y la preocupación por la inminente muerte". Posteriormente, Kimball (1969), descubrió que la mortalidad más alta se verificaba entre los pacientes deprimidos antes de la operación. En virtud de la estrecha conexión entre depresión y desesperanza, podemos postular que la falta de esperanza es un factor de riesgo en las cirugías. Las evidencias extraídas en diferentes investigaciones confirman esta hipótesis.

Hace unos años atrás, investigamos la esperanzadesesperanza en pacientes quirúrgicos que llegaban al Sanatorio Adventista del Plata, en Entre Ríos, Argentina, donde trabajábamos, para ser operados de cálculos de la vesícula biliar (Pereyra, 1995, 210-221). Estudiamos un grupo de 60 pacientes de ambos sexos. Antes de la cirugía les administramos nuestro Test de la Esperanza-Desesperanza (TED) y otras pruebas de evaluación. Luego, indagamos la evolución posoperatoria durante la internación y en un seguimiento seis meses después del alta. Evaluamos los indicadores clínicos (vómitos, dolor, temperatura, tiempo de internación, uso de sonda nosogástrica, entre otros), los controles médicos, los informes de enfermería, las intervenciones realizadas, las posibles complicaciones y todos los datos que pudieran ser de interés según el registro de la Historia Clínica del paciente. Los resultados del test tuvieron promedialmente un alto puntaje de esperanza, siendo la mayoría personas con una fe religiosa prác- tica y una actitud positiva ante el futuro. Como la investigación se realizó en un sanatorio confesional (Sanatorio Adventista del Plata) era esperado esos resultados. Tales datos presumían un buen pronóstico en la evolución posoperatoria como efectivamente ocurrió, especialmente durante el período de la internación. Seis meses después de la externación realizamos el seguimiento en 35 pacientes (58\%) que logramos ubicar. Evaluamos varios parámetros de las condiciones de la salud física, la salud mental y el estado general del paciente en ese momento y durante los 6 meses anteriores. Los resultados fueron impresionantes y sugestivos, quienes habían obtenido puntajes bajos de esperanza informaron haber padecido o estar sufriendo diferentes malestares y síntomas físicos y psíquicos, a diferencia de los esperanzados que lograron una evolución óptima. La correlación entre la esperanza y el estado psicofísico fue altamente significativa $(r=-.61, p<.001)$, ratificando la hipótesis de la capacidad predictiva de la esperanza sobre la salud.

Hay muchos otros estudios que han realizado investigaciones semejantes que sería tedioso citarlos. Quizás uno de los más interesantes sea el realizado por el Dr. P. Holly y su equipo de Gran Bretaña (2003), con mujeres con cáncer sometidas a una mastectomía. Indagaron dos grupos de mujeres (de 52 años de edad promedio), uno de quienes hicieron solamente la mastectomía ( $n=34)$ y el otro que simultáneamente le hicieron otra cirugía de reconstrucción de los senos $(n=30)$. Es sabido que la mutilación de esas partes del cuerpo tiene efectos devastadores sobre las mujeres, produciéndoles mucha angustia, fuertes emociones negativas sobre sí mismas y su propio cuerpo, que afectan sensiblemente la autoestima personal y la intimidad de la pareja. En esas condiciones, muchas mujeres se deprimen y entran en un estado agudo de desesperanza y desamparo -helpless/hopelessness-, pero otras luchan para sobreponerse y seguir adelante, actitud que se denominó fighting spirit, "espíritu de lucha", que la estimamos como una dimensión de la esperanza (Pereyra, 1997). ¿Qué sucedió con las pacientes de Holly? ¿Sería que aquellas que le colocaron la prótesis estuvieron mejor?

Se siguió la evolución de ambos grupos hasta 15 meses después de la cirugía para observar si quienes habían quedado sin senos estaban peor que las que ha- 
bían recibido el implante. Fue una sorpresa para los investigadores hallar que no había ninguna diferencia entre los dos grupos de mujeres. Sin embargo, encontraron diferencias altamente significativas en la actitud que adoptaron algunas mujeres de los dos grupos para afrontar la pérdida. Aquellas que exhibieron un alto "espíritu de lucha" no se deprimieron ni se pusieron ansiosas, en contraste con las desesperanzadas que informaron altos niveles de depresión y trastornos de la ansiedad, perjudicando el proceso de la recuperación.

\section{LA ESPERANZA Y EL SISTEMA INMUNO- LÓGICO}

"Siempre hay un margen dentro del cual la vida puede vivirse con un significado, y hasta con cierta alegría, pese a la enfermedad" Norman Cousins $(1981,171)$.

Ya hemos visto que la esperanza actúa sobre el sistema endocrinológico, ¿será que también actúa sobre el sistema inmunitario? Hace unos años, el caso de Norman Cousins, conocido director de la Saturday Review, conmocionó el mundo de la medicina. Cousins sufrió una grave enfermedad colágena, "espondilitis anquilosante", una rara parálisis progresiva que ataca piernas, cuello y espalda, y que produce fiebre y agudos dolores en todo el cuerpo. Los especialistas que lo trataron le dieron muy pocas esperanzas de vida: sólo un paciente de cada 500 había logrado recuperarse. Cousins, decidió aferrarse a esa remota posibilidad. Razonó que si el estrés y las emociones negativas debilitan las defensas del organismo, favoreciendo la vulnerabilidad a las enfermedades, seguramente las emociones positivas producirían alteraciones químicas que devolverían la salud al cuerpo. Entonces, paulatinamente dejó las pastillas (analgésicos, somníferos y hasta las drogas antiinflamatorias) que le estaban administrando en altas dosis, sustituyéndolas con cantidades crecientes de vitamina $\mathrm{C}$ y el pleno ejercicio de las emociones afirmativas. Supuso que de esa manera mejoraría la acción de su sistema inmunológico.

Sin embargo, se le presentó un problema: "Era bastante fácil tener fe, amor y esperanza, pero -se dijo¿y la risa? Nada es menos divertido que yacer de espaldas con todos los huesos de la columna vertebral y las coyunturas doloridos. Lo indicado era seguir un programa sistemático. Pensé que sería bueno empezar con unos filmes cómicos" (Cousins, 1981, 43). Así empezó a automedicarse la droga de la risa: "El plan dio resultado. Descubrí con gozo que diez minutos de genuinas carcajadas producían un efecto anestésico y me permitían dormir por lo menos dos horas, sin ningún dolor. Cuando desaparecía el efecto analgésico de la risa, conectábamos otra vez el proyector (de cine); no era raro que esta nueva sesión derivara en otro intervalo de sueño indoloro" (Ídem, 44). No sólo la risa producía efectos analgésicos e inductores del sueño, también bajaba la eritrosedimentación, indicador del grado de infección o inflamación, en los análisis de sangre. Paulatinamente pudo recuperar los movimientos de los dedos sin sufrimiento, incorporarse en la cama, ampliar el radio de giro del cuello y al cabo de algunos meses mejoró la movilidad hasta prescindir de las abrazaderas metálicas para caminar.

Cousins relató su extraordinaria experiencia en el New England Journal of Medicine, una de las revistas más prestigiosas del mundo médico. Su nota desencadenó el envío de más de 5000 cartas, la difusión en periódicos especializados y de divulgación de todo el mundo, y fue la base de un libro que durante varios años ha estado en la lista de best-sellers en los EEUU, Anatomy of an Illnessm, traducido al español como: La voluntad de curarse. El punto de vista del paciente.

Cousins concluyó su libro con una sabrosa y significativa anécdota. Refiere que 10 años después de su enfermedad, por una rara casualidad del destino, en una multitudinaria calle de Nueva York se cruzó con uno de los especialistas que había formulado el diagnóstico fatal de parálisis progresiva invalidante y había asegurado que prácticamente no tenía ninguna posibilidad de sobrevida. "Se sorprendió manifiestamente al verme. Le tendí la mano y él la estrechó en la suya. Yo quería dejar algo en claro y pensé que la mejor forma de hacerlo era con un saludo lo bastante firme como para impresionarlo, así que en vez de soltarle la mano se la apreté más, hasta que él hizo una mueca de dolor y me pidió que se la soltara. Dijo que, en vista de ese apretón de manos, no necesitaba preguntarme acerca de mi estado actual, pero que ansiaba saber qué había detrás de esa recuperación. Le respondí que todo había comenzado en el momento en que decidí que algunos expertos no poseen, en realidad, conocimientos sufi- 
cientes para condenar a un ser humano. Añadí que esperaba que tuviera cuidado con lo que les decía a los demás: algunas personas podrían creer en sus palabras y eso sería el principio del fin" (Ídem, 184). Esa sana rebeldía hacia los diagnósticos fatalistas es una de las expresiones de la esperanza y, por el contrario, entregarse al derrotismo es ser víctima de la desesperanza.

Si bien los manuales de inmunología clínica, hasta principios de la década del 80, no hacían mención a la intervención de las variables psicológicas sobre el sistema inmune y aún hasta promediar esa década se discutía tal incidencia (Hall, 1985; 1987), en la década de los 90 las evidencias fueron acumulándose, hasta reconocerse actualmente que los factores psicológicos son capaces de influir en el sistema inmunológico, fortaleciéndolo o debilitándolo, y afectar por esa vía los procesos salud-enfermedad. Hay una bibliografía creciente en los últimos años que explican como las variables psicológicas afectan el sistema inmunológico en diferentes áreas de su funcionamiento.

Un ejemplo ilustrativo es el estudio de dos grupos de pacientes con depresión crónica o distimia, tratados con antidepresivos y psicoterapia, quienes fueron evaluados en los niveles de depresión, esperanza y la reacción inmune en los linfocitos T y B. Se encontró que el porcentaje de las células B -una variable del sistema inmunológico-, correlacionaba negativamente con los puntajes de esperanza, tanto en la etapa pre-droga $(r=-$ $0.51 ; \mathrm{p}<.05)$ como en el seguimiento 3 meses después $(r=-0.24)$ (Udelman, 1985, 1071). En otro estudio de Baron y colaboradores (1990), evaluaron algunas dimensiones de la esperanza en lo que denominaron "soporte social". Hipotetizaron que la percepción del soporte social comprende 6 dimensiones:

1) alianza confiante (reliable alliance), "el conocimiento de que uno puede contar con ayuda tangible cuando esta es necesitada";

2) guía (guidance), "aviso e información de una fuente de confianza";

3) afirmación de los méritos (reassurance of worth), "reconocimiento de las habilidades y competencias propias";

4) apego (attachment), "intimidad que fomenta un sentido de seguridad";

5) integración social (social integration), "grupo con intereses similares"; y
6) proveer apoyo (provide nurturance), "sentimiento que uno es necesitado por otros".

Estas variables fueron estudiadas junto con otras correspondiente a la función inmune (la proliferación de los linfocitos T por la acción mitogénica de las células mononuclear de la sangre periférica; la proliferación de los linfocitos $\mathrm{T}$ por acción del mitógeno concanavalin A; la actividad de las Killer cell; el porcentaje de linfocitos generales y de linfocitos $\mathrm{T}$ ) en personas con alto niveles de estrés. La muestra estuvo constituida por cónyuges de pacientes con cáncer urológico ( 2 hombres y 28 mujeres), en momentos que traían al cónyuge a la quimioterapia. Se encontró fuertes correlaciones positivas entre el soporte social y la actividad inmunológica.

Por otra parte, Goodkin (1986), postuló que la desesperanza incrementa el nivel del cortisol, haciendo decrecer la actividad de los linfocitos T. Algunos autores estimaron que el cortisol es la hormona de la esperanza o, mejor dicho, de la desesperanza, ya que los altos valores se corresponde con el ánimo decaído. Así, en un estudio clásico, se observó que los padres cuyos hijos padecían cáncer presentaban niveles de cortisol elevados. Sin embargo, la cuantía de dicho aumento variaba con el modo en que cada progenitor abordaba el problema. Se encontraron niveles de cortisol mucho más bajos en los padres que tenían defensas psicológicas contra la ansiedad; por ejemplo: fe religiosa, capacidad para negar la gravedad de la enfermedad del hijo o la tendencia a desplazar la ansiedad dedicándose por completo al cuidado del paciente". Concluyó que "lo importante es la actitud, que se debe diferenciar entre lo que se puede y no se puede cambiar (y aceptar, en su caso, lo último) y que hay que buscar asideros de control y de predictibilidad en circunstancias difíciles". Esta actitud está muy relacionada con nuestra manera de concebir la esperanza.

Francis Brennan y Carl Charnetski (2000), descubrieron que altos puntajes de pesimismo y desesperanza afectaba negativamente la función inmune, ya que disminuía la inmunoglobulina $\mathrm{A}$, uno de los anticuerpos más abundantes del organismo, dejando el cuerpo más vulnerable a las infecciones. Probablemente la más importante autoridad en el tema de los factores psicológicos y la inmunología sea la Dra.Suzanne 
Segerstrom, de la Universidad de Kentucky. En el año 2001, publicó un artículo titulado: Optimism, Goal Conflict and Stressor-Related Immune Change, donde presenta dos investigaciones realizada con estudiantes de abogacía. En ambos confirmó que el optimismo actúa sobre el sistema inmunológico, al examinar varios tipos de células de la sangre periférica, como fueron la CD4+ célula T, CD3+CD8+, entre otras. Otro estudio semejante de Segerstrom fue realizado en el 2005, donde nuevamente encontró evidencias entre el optimismo y los procesos inmunológicos, concluyendo que "los pensamientos positivos producen efectos positivos" aunque no siempre, dependiendo los resultados del grado de estrés que intermedie. Pero el estudio más importante, elaborado con rigurosos criterios científicos, fue el realizado por Segerstrom y Millar (2004) en el cual reportan el informe de un metanálisis con más de 300 investigaciones efectuadas en los últimos 30 años, que describen las relaciones entre los diferentes parámetros del sistema inmune humano y distintas variables psicológicas. Allí clasifican grados y tipos de estrés y como inciden cada uno en el sistema inmunológico. Por supuesto, el optimismo o la esperanza, como el pesimismo o la desesperanza aparecen jugando un rol importante.

\section{LA ESPERANZA EN HIV/SIDA}

La verdadera desesperanza no nace ante una adversidad obstinada, sino que surge cuando ya no se ve razón para lucha.

"Todo lo que aquí se hace, aquí se paga...", esa fue la sentencia que, con patético dramatismo, pronunció Juan Carlos (21, soltero) al recibir el informe del laboratorio con el análisis del HIV, Human Immunodeficiency Virus, que indicaba que era positivo. Hacía dos días que estaba internado para tratar su adicción. En la primera consulta me describió la triste historia de su vida y su caótico mundo familiar. Sus padres se habían separado, después de una turbulenta y desgraciada vida en común. Su madre era una "histérica, impulsiva y gritona", que lo desquiciaba, "No la soporto, me pone loco cuando grita; la mayoría de las veces la mando a freír churros..." En cambio, el padre era "muy responsable... de carácter más bien fuerte", aunque no toleraba la relación que tenía "con esa mujer", la pareja con quien convivía. "Está totalmente desubicado, no es la persona para él, ¿sabe? -enfatizó indignado, mientras movía el índice derecho en forma de taladro sobre su cien, en el típico gesto de locura-. ¡Es una mujer mala! ¿Entiende?”. Espantado por ese espectáculo repulsivo que estaba protagonizando su progenitor, Juan Carlos buscó afecto, olvido y estímulo "en la calle". Hacía "cuatro o cinco años" que transitaba por aquellos territorios oscuros y salvajes, que paulatinamente lo arrastraban hacia zonas tenebrosas y crueles de pesadilla y delirio, los caminos de la desesperanza.

- Yo pienso que lo probé todo -confiesa amargado-, marihuana, Aseptobrón, coca, heroína, LSD...

- ¿Hiciste algún intento para dejar?

- Lo intenté, pero allá no se puede, el ambiente está muy podrido; salís y enseguida te invitan... -ante mi gesto de incredulidad, agrega-. No sé, pienso que también soy un poco débil...

Se encogió de hombros, exhaló un lánguido suspiro lastimero, lanzando una mirada lejana. Cuando recuperó el ánimo, prosiguió:

- Opté por encerrarme en casa. Pasaba una semana, diez días, pero siempre aparecía alguno a buscarme. Usted sabe que ningún drogadicto se "pica" (inyecta) solo. Cuando uno anda solo es para buscar a alguien. Siempre se "curte" (droga) con otro.

Después de esa digresión informativa, retomó el hilo.

- La última vez estuve como dos semanas encerrado. Cuando salí me encontré con un amigo. No quería curtir, pero no fui capaz de decir no en ese momento...

Juan Carlos no fue capaz de decir "no" y se convirtió en uno más de las decenas de millones de portadores del VIH, una nueva víctima de la peste rosa. A partir de ese momento, los senderos de la ilusión de Juan Carlos se transformaron en fangosas y resbaladizas calzadas de terror. Fue presa del pánico, se violentó con el personal del Sanatorio, cometió algunos hurtos y finalmente fue detenido por la policía. Nunca más supe de él. 
¿Por qué tantos se exponen gratuitamente a la muerte optando por mantener el difícil equilibrio sobre el filo del abismo? Otro drogadicto me comentaba: "En realidad, sabes que alguien puede tener SIDA, que te podes contagiar, pero es como jugar a la ruleta rusa; en la droga se está en eso". ¿Qué extraño y siniestro placer produce el "jugar a la ruleta rusa", exponerlo todo en un fortuito e impiadoso acto del destino? Desde el mono verde en el centro del África -supuesto portador del antecesor del virus del SIDA- hasta Juan Carlos, el VIH viajó decenas de miles de kilómetros recorriendo Haití, Estados Unidos, Europa, hasta finalmente llegar a América Latina y la Argentina, donde vivía nuestro paciente. En ese largo itinerario de muerte, el virus cabalgó sobre muchísimos hombres y mujeres que, en la mayoría de los casos, se prestaron gozosamente a ser inoculados. El tratamiento con decenas de drogadictos me ha llevado a la conclusión que esa atracción por la muerte es el resultado de un profundo vacío interior, de la ausencia de un sentido de vida y de la desesperanza que se aferra a la ilusión o al delirio de encontrar algo que llene la existencia.

Charles Baudelaire, en su libro "Los paraísos artificiales", describía ese loco magnetismo como "magnificencias de luz, esplendores de gloria y cascadas de oro líquido", una suerte de acción hipnótica que anula la razón y lleva inexorablemente a la destrucción. Son fulguraciones mágicas de exóticas revelaciones y recompensas gratificadoras que impresionan los sentidos, como los juegos pirotécnicos en las noches de fiestas que rápidamente se disuelven en la densa oscuridad de la nada, quedando el vacío y la frustración. Esa seducción por tales espejismos florece en los terrenos del hastío y la tristeza bajo los auspicios de los poderes de las tinieblas. En contraste, en la esperanza late el sentido de la vida que ilumina nuevos horizontes de promesa, potencializando las fuerzas vitales y movilizando las aspiraciones por nuevas realizaciones enriquecedoras.

Las investigaciones con sidóticos se multiplican continuamente en los congresos internacionales y las publicaciones crecientes que aparecen en las revistas especializadas (v.gr., Health Psychology). En un trabajo clásico, Blaney y su equipo (Smith, 1989), evaluando un grupo de homosexuales durante las primeras etapas de infección del VIH, descubrieron que las perso- nas con espíritu aguerrido, temperamento vigoroso y esperanzadas tenían mejores funciones inmunológicas que aquellos que eran apáticos, depresivos y desesperanzados. Los investigadores de la Universidad de Miami estudiaron la correlación entre el sistema inmunológico y diferentes tipos de personalidad, interrogando a 49 sidóticos acerca de su modo de vida y la forma de enfrentar y resolver los problemas. Paralelamente examinaron las respuestas de varios componentes del sistema inmunológico, como la habilidad de los linfocitos para responder a los estímulos. Encontraron que las personas esperanzadas, que tomaban "el toro por las astas" y enfrentaban los problemas con voluntad decidida eran capaces de resistir el virus mejor que los pasivos y abúlicos. Los que se resignaban, retraían y fácilmente perdían la esperanza, exhibían un alto nivel de inmuno-globulina y anticuerpos, indicadores de mayor infección. Por el contrario las personalidades aguerridas y luchadoras que hacían frente a los problemas y dificultades, tenían una mejor respuesta de las células NK ("natural killers cell") y de la actividad de los linfocitos.

Carson et al. (1990), examinaron el impacto del Sida en 65 hombres (edades 22-70 años), con HIV positivo, a los cuales les administraron la Escala de Desesperanza de Beck y la Escala de Bienestar espiritual. Encontraron mejores respuestas del sistema inmunológico en quienes tenían altos puntajes de esperanza y de bienestar espiritual, en comparación con los que reportaban no tener ninguna afiliación religiosa. Otro estudio con resultados similares fue hecho por Janice Tomakowsky y otros profesionales de Detroit (2001), quienes midieron dos tipos de optimismo y los compararon con síntomas del HIV y el conteo de células T CD4, en un seguimiento durante dos años. Una de las conclusiones fue que "las medidas de optimismo estuvieron relacionadas con mejor percepción de la salud en hombres infestados de HIV".

Quizás uno de los trabajos recientes y más interesantes sobre los pacientes con SIDA y los efectos de la esperanza, sea el realizado por Meighan Rogers y colabores de la Escuela de Medicina de la Universidad de Yale (2005), quienes investigaron 172 hombres y 92 mujeres con SIDA (gay, lesbianas y bisexuales) que estaban en duelo por la pérdida de la pareja, un amigo íntimo o un familiar cercano ocurrida en el último mes. 
El estado de duelo, en cualquier persona, produce pesar y angustia, pero en los enfermos con SIDA se agrava la situación, generando estrés postraumático, trastornos del sueño, uso de sedantes, desmoralización, uso de drogas y de servicios psicológicos. Lo que interesaba indagar era como afrontaban los sujetos de la muestra el pesar producido por el fallecimiento del ser querido, que mecanismos utilizaban para superar o no superar la situación y como esas actitudes incidían sobre su sistema inmunológico. Descubrieron que aquellos que utilizaban recursos activos y bien adaptados para afrontar el problema (v.gr., confrontación, autocontrol, búsqueda de apoyo social, aceptando la responsabilidad, resolviendo el problema y reformulación) eran los que tenían altos niveles de optimismo, en contraste con los desesperanzados que recurrían a la evitación como fórmula de afrontamiento. Se concluyó que es muy importe realizar ayudar a los pacientes de SIDA deudos con intervenciones que "enfaticen el optimismo, la esperanza y enfrentamiento activo que puedan decrecer la depresión y el dolor y subsecuentemente incrementen el estado de la salud física", (Ïdem, 356) ya que el "optimismo está asociado con triunfar sobre la adversidad" (Ídem, 344). En resumen, hay esperanza para los enfermos infectados del VIH ya que la esperanza ha sido considerado "esencial para vivir con SIDA" (Rabkin et al., 1990).

\section{¿CÓMO COMBATIR EL CÁNCER?}

"La esperanza ha sido identificada como un componente vital para los individuos con cáncer”. M. L. Nowotny $(1989,57)$

Ya los clínicos del siglo XIX habían descubierto que el "cáncer es el resultado de la herencia nerviosa. Es especialmente en los sujetos deprimidos, cuyas funciones nerviosas se encuentran apagadas y cuya vida se desenvuelve bajo esa acción depresiva, que el cáncer puede hacer su aparición" (Zwanck, 1980, 379). En la actualidad, un número creciente de investigaciones destacan la gravitación de los componentes emocionales y psicoespirituales en la etiología y evolución del cáncer, como en el tratamiento y en las etapas avanzadas de la enfermedad. ¿Cuáles son las características principales de la psicología del enfermo oncológico? Entre los rasgos emocionales más significativos asociados a la aparición del cáncer se citan el duelo, la desesperanza, la depresión y el abatimiento anímico (Keinan et al., 1991-92).

Ya Schmale y colaboradores (1966), habían observado que "muchas pacientes con cáncer habían experimentado sentimientos de desesperanza durante cierto tiempo anterior a la aparición de la enfermedad". Con esa hipótesis estudiaron 40 mujeres con Papanicolaou Clase III, cuyas células son consideradas sospechosas pero que no garantiza el diagnóstico de cáncer. Los resultados de aplicar varias pruebas, entrevistas y la realización de la biopsia demostraron que, "un alto potencial de desesperanza y/o recientes sentimientos de desesperanza predicen la presencia o ausencia de cáncer cervical en las mujeres". Una investigación posterior (1971) del mismo equipo, reportó que en 68 mujeres con cáncer de útero, la desesperanza, la depresión y la ausencia de un proyecto existencial fueron las "condiciones permisivas que favorecieron la evolución neoplásica". Por su parte, Goodkin et al. (1986), utilizando técnicas confiables de validación de la desesperanza confirmaron, en una muestra de 73 casos que presentaban distintos niveles de desarrollo de cáncer de útero, que los "altos niveles de desesperanza, alienación social y ansiedad somática" fomentan la invasión del carcinoma cervical. Resultados similares encontró Jensen (1987) en la evolución del cáncer de mama. Otro estudio impactante afirma haber descubierto una relación inversamente proporcional entre las metástasis y la esperanza, de modo tal que, cuanto más disminuye ésta más rápidamente se extienden aquellas, es decir, a más desesperanza más se expande el cáncer (citado por Seva, 1979, 476).

No sólo la desesperanza juega un rol importante en la génesis y desarrollo del cáncer, también se descubrió que la esperanza cumple una función decisiva en la recuperación del enfermo. En un estudio realizado con 22 pacientes, estudiados durante un período que llegó hasta 20 años, que tuvieron una "regresión espontánea" del cáncer, es decir, que desapareció sin causa aparente, encontraron tres características comunes entre los que se curaron:

“1) aunque la reacción inicial al conocer el diagnóstico de la enfermedad fue traumática, todos ellos la aceptaron y tomaron la determinación de no claudicar y luchar contra ella; 
2) en cuanto se recuperaron del episodio agudo continuaron su vida normal, y

3) desarrollaron cogniciones de confianza en su curación, y nunca perdieron la esperanza de recuperarse" (Kennedy et al., 1976).

Probablemente el estudio más importante sea la revisión de la bibliografía sobre el tema realizada por Lin y Bauer-Wu (2003), quienes analizaron 177 artículos publicados entre 1985 y el 2001. De esas investigaciones, 43 artículos indagaron el bienestar psico-espiritual de pacientes en avanzado estado de cáncer, en 14 países de Norteamérica, Europa, Asia y Australia. Las conclusiones principales que obtuvieron los autores fue que "vivir con significado y esperanza", "es muy importante para los individuos que padecen cáncer avanzado", ya que "es un factor significativo en la adaptación a la enfermedad, la reducción del estrés psicológico, el acrecentamiento del bienestar psico-espiritual y la calidad de vida, y en el desarrollo de un sentido de buena muerte" (Ídem, 78).

En síntesis, hay que reconocer con Hickey (1989), que "la esperanza constituye un elemento esencial en la vida de quienes tienen cáncer". Por lo que se recomienda que el personal de los servicios de oncología y los trabajadores sociales (Itzhaky et., 2004).conserven un "clima esperanzado" (Given et al., 1993) y hagan un esfuerzo especial por mantener viva la esperanza del paciente, como asimismo de los familiares, que a veces se deprimen más que el propio paciente (Benzein et al., 2005). Esa actitud es esencial para enfrentar de la mejor manera posible la malignidad de la enfermedad.

\section{LA ESPERANZA EN LOS TRASTORNOS CARDIOVASCULARES}

“El 'corazón' era la palabra del amor y de la vida en los tiempos románticos del ensueño, la poesía y la leyenda. Hoy el corazón perdió esos líricos y vaporosos contenidos al convertirse en el asesino $N^{o} 1$ de la humanidad."

¡Corazón! Dulce y delicada palabra. Poética expresión que contiene tiernos sentimientos, emociones íntimas, cálidas añoranzas e imágenes de seres queri- dos. Resonancias idílicas que palpitan nostálgicos recuerdos en el añoso tronco de un árbol, donde se dibuja el emblema del amor con nombres de una pareja atravesados por la flecha de Cupido. ¡Corazón! Altar de la pasión, confesionario de dichas e infortunios, santuario del alma, residencia de lo eterno. Hoy el corazón perdió esos significados poéticos al convertirse en la principal causa de muerte en casi todos los países del mundo. Cuando un inquietante estremecimiento sacude el pecho, ya no surgen las fantasías eróticas, sino irrumpe el espectro luctuoso de lo fatal con temblorosos escalofríos. El órgano silencioso que ahora galopea frenéticamente, oprime el pecho y genera sordos rumores o agudos dolores, hoy produce una sirena ululante por el tránsito urbano avanzando raudamente hacia una unidad de emergencia coronaria. Así el corazón se convirtió de símbolo del amor en heraldo de la muerte.

¿Existe alguna relación entre la esperanza y las enfermedades del corazón? ¿Puede la confianza en el futuro salvaguardar las arterias y mejorar la circulación sanguínea? Ya en 1984, afirmaban Crisp y McQueen: "Dentro de la población general los individuos destinados a sufrir un infarto de miocardio poseen un carácter más obsesivo y pesimista". Actualmente los avances de la investigación son concluyentes y no ofrecen ninguna duda. Varias revisiones de la bibliografía que incluyen decenas de estudios epidemiológicos han concluido que la depresión y la ansiedad predicen una enfermedad coronaria aún después de controlar los tradicionales factores de riesgo, como son el colesterol, la presión arterial, sedentarismo, obesidad y el tabaquismo (v.gr., Gallo et al., 2003; Rugulies, 2002; Suls et al., 2005). En un metanálisis que incluye las principales investigaciones en la materia de las últimas cuatro décadas, realizados por Suls y Bunde (2005) de la Universidad de Iowa, resumieron los hallazgos de 24 estudios, que incluyen muestras que oscilaron entre 730 a 9563 pacientes, que fueron seguidos en la evolución de la enfermedad coronaria de 4 hasta 15 años, encontraron que la depresión es un indicador altamente significativo de los trastornos cardiovasculares, junto con la ansiedad y la hostilidad. La depresión fue definida de acuerdo con el Manual Diagnóstico de las Enfermedades Mentales de la Asociación Psiquiátrica Norteamericana, el DSM-IV, incluyendo dos síntomas que han sido objeto de estudios 
específicos, estos son la vital exhaustación y la desesperanza (Ídem, 262). Por "vital exhaustación" se entiende un estado de "falta de energía, irritabilidad y desmoralización" (Ídem, 263), en tanto, la desesperanza se focaliza en los aspectos cognitivos de la depresión, esto es, la percepción de ineficacia y pesimismo.

En otro estudio, Leedham et al. (1995), explorando las relaciones entre las expectativas positivas u optimismo, el bienestar psicológico y la salud física en 31 pacientes cardíacos a los cuales les transplantaron el corazón en el Vanderbilt University Medical Center (USA), también encontraron correlaciones significativas entre los altos puntajes de expectativas positivas en el preoperatorio con un buen ajuste psicológico y altos niveles de salud física obtenidos seis meses después de la cirugía. Los investigadores aseguran que un alto nivel de optimismo antes de un trasplante tiene la virtud de predecir una buena evolución física y psicológica.

¿En que medida incide la esperanza/desesperanza entre los factores de riesgo cardiovascular? Esqueda (1993), de la Universidad de Los Andes, Venezuela, estudió los efectos de la esperanza-desesperanza en 21 infartados que habían sufrido el accidente cardiovascular en un período inferior a un mes. Observó que el shock producido por el impacto de la enfermedad "rompe los proyectos personales y coloca al individuo en una actitud de espera incierta donde no hay cabida para imaginar caminos nuevos y desafiantes a largo plazo" (Ídem, 460). Al disminuir la esperanza aumenta la creencia en los peligros externos, disminuye las expectativas de logro y se exacerba la ansiedad generalizada. Por lo cual, puede inferirse que una alta esperanza promueve la tranquilidad de espíritu, una actitud positiva con respecto a los resultados y la confianza interior en sí mismo y en Dios, que amortigua los temores y da un sentimiento de mayor seguridad.

\section{LA DESESPERANZA Y LA PSICOPATOLOGÍA}

"Hay personas que dan la impresión de un destino que las persigue,

De una orientación demoníaca de su existencia." Segismund Freud

"El filósofo francés existencialista, Gabriel Marcel (1954), ha definido la desesperanza como la voluntad de deserción. Se trata de una actitud de abandonarse y retirarse de la lucha, de renunciar a todo, de no querer saber más nada. Por su parte, Lain Entralgo $(1957 ; 1978)$, acuñó el término diselpidia para hablar de la falta de esperanza ("dis", prefijo negativo y "elpis", del griego, esperanza), explicándolo como la patología del esperar humano. Pero, quizás la definición más lúcida y precisa haya sido la formulada por Schmale y Engel (1967), quienes llamaron a la desesperanza "the given up-given up complex", que podría traducirse como el síndrome de la renuncia. Se trata de sentimientos de desamparo y renuncia, de impotencia y derrotismo, de imposibilidad de recibir ayuda, pérdida de confianza en las relaciones interpersonales, vivencia de ruptura en la continuidad biográfica, refugio y aferramiento al pasado con pérdida de los proyectos para el futuro. Es, pues, "la desesperanza -siguiendo a Lain Entralgo-, esa especie de retracción de la existencia sobre sí misma ante la vacía nihilidad de lo porvenir" (Pereyra et al., 2005, 52).

¿Por qué la gente cae en esos abismos del derrotismo y de renuncia? ¿Qué produce la desesperanza? Una investigación notable realizada por un grupo de estudiosos de Finlandia, dirigidos por Haatainen (2003), descubrió que la desesperanza del adulto tiene una relación muy importante con eventos traumáticos experimentados durante la infancia. Examinaron un grupo de 1598 adultos, entre 25 y 64 años, quienes completaron una serie de pruebas de evaluación, especialmente en los niveles actuales de desesperanza y si habían sufrido algún tipo de episodio o situación grave cuando niños, por ejemplo, pobre relación con sus padres, infelicidad, castigos físicos, violencia doméstica, abuso de alcohol de los padres y un tratamiento educativo muy duro. El análisis estadístico de la información encontró relaciones significativas entre las experiencias traumáticas en la infancia y la desesperanza durante la adultez.

Como podemos apreciar las investigaciones han puesto de manifiesto la importancia etiopsicopatogénica de la desesperanza. Es de destacar que en el DSM-III$\mathrm{R}$, aparecían los "sentimientos de desesperanza" como un síntoma o indicador diagnóstico en 21 cuadros clínicos diferentes (del eje I), desde los trastornos mentales orgánicos de tipo demencial, a las drogadicciones, depresiones, intoxicaciones, trastornos psicóticos y tras- 
tornos adaptativos. Por nuestra parte, realizamos un estudio con una muestra de 41 personas que contestaron el Test de Esperanza-Desesperanza (TED) del autor (Pereyra, 1995) y el Inventario de Minnesota, el MMPI-2, encontrando que mayoría de las escalas psicopatológicas tuvieron alta correlación mutua, en tanto, los resultados totales del MMPI-2 y la escala global del TED también encontró una alta correlación de $\mathrm{r}=-.45$ ( $\mathrm{p}<.001)$, ratificando la conexión entre desesperanza y psicopatología (Ídem, 162-175).

Donde los reportes de las investigaciones son abrumadores y las evidencias innumerables, contundentes e irrefutables es en la relación de la desesperanza con la depresión. Las evidencias indican que la desesperanza es el factor de mayor peso en el incremento de la tristeza o disforia (Reff et al., 2005), la producción de las depresiones (v.gr., Beck, 1963; Drake et al.,1986) y la melancolía (Adamson y Schmale, 1965). Beck afirmó categóricamente que "la desesperanza es el corazón de la depresión" (Beck, 1967), confirmándolo con una multitud de evidencias, derivadas de estudios propios y de otros investigadores. Por ejemplo, se ha demostrado que la desesperanza discrimina significativamente entre grupos de depresivos y no depresivos (Alloy et al., 1987) y es un predictor de severidad de una depresión (McCranie et al., 1992). Kashani y otros (1992), en una síntesis de numerosos estudios relacionó la desesperanza con la depresión en términos de atribuciones, motivación y gratificación aplazada, afirmando la importancia de la prevención de la desesperanza en la escuela para evitar las depresiones. También propuso un tratamiento utilizando técnicas cognitivo-conductuales.

Es de destacar que las investigaciones acerca de la desesperanza y la depresión, tanto en la teoría como en la psicoterapia, han tenido un amplio desarrollo entre los cognitivistas y entre los partidarios de la teoría de la atribución. Estos últimos han hecho una propuesta novedosa, muy importante desde el punto de vista clínico, ya que han presentado un nuevo tipo de depresión, llamada la "Depresión Desesperanzada", Hopelessness Depression. Abramson, Metalsky y Alloy (1989), fueron quienes revisando la teoría del desamparo aprendido postularon la existencia de un subtipo de depresión, producida por distintos causas (necesarias, suficientes y contribuyentes), donde incluyeron los altos niveles de estrés, la vulnerabilidad, la tendencia depresógena, el estilo atribucional y otros factores participantes como la falta de apoyo social. Los síntomas identificados de la Depresión Desesperanzada fueron: disminución de la voluntad, tristeza, falta de energía, apatía, trastornos del sueño, dificultades de concentración, ideas negativas y la intención suicida. Desde esta perspectiva, la desesperanza es definida como "una expectativa de resultados altamente deseados que no ocurrirán o de resultados altamente aversivos que ocurrirán y que nada sucederá para mejorar esta situación" (Metalsky et al., 1992, 667). Es de hacer notar, que aunque el aporte es sugestivo no ha producido el impacto entre los especialistas que generó otras contribuciones de la teoría atribucional, como el "estilo explicativo".

Nos parece importante destacar que algunos estudios han corroborado que la desesperanza es aún más grave que la depresión. Srikumar y colaboradores (2000) han estudiado el rol de ambos cuadros -depresión y desesperanza- en personas de tercera edad gravemente enfermos (infartados, con cáncer de estómago o de cerebro, Alzheimer, neumonía y diabetes), que requerían aplicarles tratamientos para salvarles la vida, como la resucitación cardiovascular, la ventilación mecánica, el suero intravenoso y la sonda nosogástrica. Fueron un total de 2503 pacientes del sexo masculino quienes fueron admitidos en la unidad de cuidados intensivos del Veterans Administration Medical Center de la Universidad de Maryland, en estado crítico, necesitados de tratamientos de emergencia. A esos fines se les pidió el consentimiento para hacer intervenciones vitales. El 29,3\% se rehusó a recibir esos tratamientos. Al evaluar tales pacientes se encontró que no era la depresión lo más numeroso sino la desesperanza. Fueron los altos niveles de desesperanza lo que se encontró estadísticamente significativo en el rechazo a los procedimientos médicos para salvarles la vida, más allá de la edad, características raciales, tipo de enfermedad y evolución de la misma. Por su parte, la depresión no tuvo una incidencia significativa.

Otra serie de investigaciones experimentales y estadísticas han revelado que la desesperanza es un componente básico en los procesos suicidógenos. Hay que reconocer que el acto de quitarse la vida puede ser motivado por una amplia gama de razones, psiquiátri- 
cas, psicológicas, genéticas, personales, familiares, psicosociales, demográficas y aún neurobiológicas. Sin embargo, la bibliografía especializada ha reconocido hasta el hartazgo que la desesperanza es uno de los factores de más peso en los suicidios (Beck et al., 1985; 1989; Cassells et al., 2005; Viñas et al., 2004). Entre pacientes con episodios depresivo mayor, en un seguimiento a cuatro años, Fawcett y otros (1987), encontraron que la desesperanza era la variable de más peso entre los suicidas y el grupo de control. También se encontró que cuando está muy alta la desesperanza aun los tratamientos con antidepresivos corren riesgo de fracasar (Papakostas et al., 2005). Pero no solamente la desesperanza es diagnóstica de ideación, intención y suicidios consumados, también tiene un carácter predictivo. Por ejemplo, Kim et al. (2003), encontraron en 200 pacientes esquizofrénicos que se suicidaron, la desesperanza fue el único predictor del suicidio.

En síntesis, puede concluirse que la desesperanza, entendida como una expresión del colapso de la esperanza, se asocia con diversos indicadores y conductas específicas patológicos, tanto en enfermedades físicas como mentales, lo cual permite sostener la hipótesis general que la desesperanza es un constructo diagnóstico y en gran medida predictivo de procesos enfermizos.

\section{LA ESPERANZA Y ALTA CALIDAD DE VIDA}

"La esperanza renace una y otra vez. en medio de la calamidad." E. Sábato $(1985,193)$

Si la desesperanza es sinónimo de enfermedad, la esperanza se identifica con la salud, el bienestar y la alta calidad de vida. La literatura demuestra consistentemente que los procesos de mejoramiento y recuperación psicológica requieren un sentido de esperanza (Roe y Chopra, 2003). En este punto, la esperanza ha sido definida "como un proceso de aceptación de la pérdida -usualmente acompañada de lucha y dolor-, que comprende la exposición y el enfrentamiento de la adversidad." Esto involucra un quehacer activo, de "trabajo" de esperanza, que tiene implicaciones de "crecimiento, desarrollo y un sentido superior de afrontamiento" (Ídem, 235).
Ampliando el tópico, Bret Simmons y su equipo (2003), han precisado el rol de la esperanza como variables mediadora de la salud. Estudiaron 950 enfermeras, de 175 centros sanitarios del sudoeste de USA, basándose en la teoría del apego de Bowby. Identificaron tres estilos de relación: 1) interdependiente: un apego seguro y autoconfiable, con flexibilidad y relaciones recíprocas; 2) contradependiente: un patrón insalubre de comportamiento, sin apertura a los otros, que evitan comprometerse, actuando profesionalmente cuando se los requieren; 3 ) sobredependiente: otro patrón insalubre, de ansiedad y ambivalencia, basado en la creencia que los otros no pueden ser ayudados. Como puede apreciarse en la figura 2 , se comprobó la hipótesis de que la esperanza es una variable mediadora entre las relaciones de interdependencia y la salud.

\begin{tabular}{l|l|l} 
Variables independientes & Variable mediadora & Resultados \\
\hline Interdependencia & & \\
Contradependencia - & &
\end{tabular}

Figura 2. Modelo de investigación basado en la esperanza como variable mediadora (Simmons et al., 2003, 367)

Otros estudios experimentales han descubierto que la esperanza o el optimismo reportan menos síntomas físicos y mejor bienestar psicológico o estado de salud (Ebert et al., 2002), aun después de sufrir una enfermedad grave o la muerte de un familiar (Kivimäki et al., 2005). Incluso la literatura la considera un agente que acrecienta la resiliencia en la infancia, constituyendo un factor protector, esto es, una influencia "que ayuda a los niños a adaptarse y a enfrentar con éxito los desafíos de la vida, en el contexto de su propia cultura y de las etapas del desarrollo" (Alvord et al., 2005, 239).

Con respecto a la relación de la esperanza con la calidad de vida, se ha encontrado que tiene relación con altos niveles de inteligencia, buen rendimiento académico, madurez y aun con el éxito laboral. El primer punto lo comprobaron Nurmi y Lainekivi (1991), al estudiar 111 adolescentes, entre 15 y 16 años, a los cuales se les preguntó acerca de sus proyectos y esperanzas futuras. Evaluaron sus funciones intelectuales 
para establecer quienes eran los de mejor nivel intelectual. Los resultados mostraron que los más inteligentes fueron los que "más frecuentemente mencionaron esperanzas concernientes a su futura educación", es decir, aquellos que presentaban más alto puntaje de esperanza.

Resultados más contundentes encontraron en la Universidad de Girona, España (Viñas et al., 2004), al examinar a 1277 estudiantes de primero y segundo años. Se investigó los niveles de desesperanza, grado de depresión, ideas suicidas y varios aspectos del comportamiento académico. Descubrieron que el 13,9\% del grupo experimentaban niveles moderados y severos de desesperanza, además encontraron que eran precisamente este grupo de estudiantes quienes se quejaban más de la universidad, gastaban más tiempo en actividades extracurriculares y evitaban más ir a los exámenes. También ratificaron un hecho conocido, la relación entre la desesperanza, la depresión y las ideas suicidas.

Otra investigación con resultados concluyentes fue realizada por C.R. Snyder y su equipo (ver Shorey et al., 2002), quienes hicieron cuatro estudios diferentes (uno de ellos siguiendo el desempeño de los alumnos durante 6 años), con grupos muy numerosos de estudiantes universitarios, comparando las respuestas de esperanza y el rendimiento escolar. Los resultados mostraron que los alumnos que reportaron mayor grado de esperanza tenían mejor performance o mayor éxito académico y menos nivel de deserción escolar, más allá de sus habilidades naturales y el grado que estaban cursando. Snyder (2002, 357-358) lo explica, diciendo: "Las ventajas de una elevada esperanza son muchas. Quienes tienen alta esperanza, comparado con la gente de bajo nivel, poseen más metas, incluso más difíciles, pero tienen éxito en lograr alcanzar sus objetivos, ya que perciben sus metas como desafíos. Revelan mayor felicidad y menos nerviosismo. Tienen habilidades superiores para afrontar la adversidad, se recobran más rápidamente de una enfermedad o un accidente y reportan menos estados de agotamiento (burnout) como dificultades en el trabajo."

Otros alcances importantes fueron descubiertos por Brackney y colegas (1992), quienes relacionaron la madurez psicosocial, encontrando que aquellos que informaban mayores puntajes de esperanza presentaban mayor grado de madurez. Hay que concluir, entonces, que los esperanzados no solo son más inteligentes sino también más maduros. Estas conclusiones han hecho pensar a Drake (1987), que la esperanza debería asentarse en el hemisferio izquierdo del cerebro, ya que es ahí donde se procesan las funciones intelectuales superiores.

La esperanza no sólo tiene que ver con la inteligencia y la madurez, también está relacionada con el estado socioeconómico de la persona y con la actividad laboral que desempeña. Aunque hay varios estudios al respecto, sólo mencionamos el realizado por Paul C. Henry de la Universidad de Sydney en Australia (2005), quien investigó la esperanza/desesperanza en relación a la ocupación laboral. Clasificó las ocupacionales en siete categorías jerarquizadas, para examinar a 20 profesionales de los dos primeros niveles y compararlos con otro grupo de 20 trabajadores manuales correspondientes a las dos últimas clases. Henry entrevistó a cada uno de los cuarenta trabajadores para conocer detalles de su historia y las principales características de vida, identificando el estilo o tipo de pensamiento de cada trabajador. Encontró que los obreros manuales mostraban un estilo de pensamiento pesimista, que lo disponían a la desesperanza, en contraste con los profesionales altamente calificados que revelaban una actitud optimista y esperanzada. 
Cuadro 1. Clasificación de las clases ocupacionales (Henry, 2005)

\begin{tabular}{lll}
\hline Tipo de clases & Clases & \multicolumn{1}{c}{ Descripción } \\
\hline Servicio profesional & 1 & $\begin{array}{l}\text { Profesionales de alto nivel, administradores del estado, gerentes de } \\
\text { grandes empresas, grandes propietarios. }\end{array}$ \\
& 2 & $\begin{array}{l}\text { Profesionales de menor grado, administradores y gerentes de em- } \\
\text { presas menores, técnicos de alto grado, supervisores }\end{array}$ \\
Intermedio & $3 \mathrm{a}$ & $\begin{array}{l}\text { Ocupaciones manuales rutinarias, secretarias, } \\
\text { Ocupaciones manuales rutinarias de menor grado, trabajadores de } \\
\text { servicios, asistentes } \\
\text { Pequeños propietarios, trabajadores por cuenta propia } \\
\text { Supervisores de trabajadores manuales, técnicos de bajo grado }\end{array}$ \\
& $4 \mathrm{~b}$ & $\begin{array}{l}\text { Trabajador manual especializado } \\
\text { Trabajador manual no especializado }\end{array}$ \\
Trabajador Manual & 5 &
\end{tabular}

LA ESPERANZA COMO FORTALEZA DEL CARACTER

\author{
"La vida significativa es emplear las fortalezas y \\ virtudes características \\ al servicio de algo que trascienda nuestra persona. \\ Martin E.P. Seligman $(2003,347)$
}

El más importante desarrollo acerca de la esperanza, según nuestro criterio, es la propuesta de la Psicología Positiva de considerarla una fortaleza del carácter, entendida como algo superior a una simple dimensión del bienestar, de la calidad de vida o de la salud. Se trata de una expresión de excelencia, de las virtudes que describen las cualidades superiores de la naturaleza humana. Veamos brevemente algunos detalles de como se gestó esta idea.

En noviembre de 1999, Neal Mayerson Director de la Fundación Manuel D. y Rhoda Mayerson de Cincinnati, citó a Martín Seligman, para lanzar juntos un proyecto. Querían desarrollar programas para jóvenes. Los críticos que evaluaron los planes a subvencionar dijeron: "No podemos intervenir para mejorar el carácter de los jóvenes hasta que no sepamos con mayor exactitud qué queremos mejorar. En primer lugar necesitamos un esquema de clasificación y una forma de medir el carácter." El consejo fue invertir el dinero en elaborar una taxonomía del buen carácter. La idea fue crear una suerte de manual de las potencialidades humanas, de la misma manera que existe un Manual Diagnóstico y Estadístico de los Trastornos Mentales (DSM), para definir un caso de alteración patológica con fiabilidad y aplicar la terapia correspondiente. El DSM ha conseguido unificar la comunidad científica de todo el mundo en los mismos criterios, haciendo posible el diálogo y el progreso. Estamos de acuerdo con respecto a la enfermedad mental, pero ¿qué con respecto a la salud? He ahí el problema.

Con el propósito de lograr una clasificación de la salud mental que fuera el eje central de la Psicología Positiva, la Fundación Mayerson decidió patrocinar un proyecto de gran envergadura. Contrataron a Christopher Peterson como director del programa. Durante tres años, el equipo de investigadores leyó los textos básicos de las principales religiones y tradiciones filosóficas a fin de catalogar lo que cada una de ellas consideraba virtudes o excelencias del carácter. Leyeron a Aristóteles, Platón, Tomás de Aquino, Agustín, el Antiguo y Nuevo Testamento, el Talmud, Confucio, Buda, Lao-tsé, el Corán, los Upanishads y otros, en total, unos doscientos catálogos de virtudes, que abarcaban casi todas las tradiciones de los últimos 
tres mil años. El resultado de ese trabajo descubrió que en todas esas fuentes se valoran seis virtudes básicas que conforman veinticuatro fortalezas. Un avance de ese estudio apareció en el 2003, en la obra de Seligman, La auténtica felicidad y el informe completo, en abril del 2004, en un volumen de 800 páginas, titulado, Carácter Strengths and Virtues. A Handbook and Classification. Allí se identifican cada una de esas fortalezas, los criterios que las definen, la tradición teórica y transcultural, las mediciones que se han elaborado y los resultados de las investigaciones. Condensa 120 páginas de referencias bibliográficas, con más de 2000 citas. Un gran esfuerzo que propone definir, categorizar y evaluar la salud psicológica remitiéndola a los valores más destacables y reconocidos de la naturaleza humana, aquellos que proclaman las eminencias de la excelencia, en lugar del inventario de los déficit y miserias humanas, las mayores aptitudes y grandezas en contraste con los estigmas y perversidades.

Recuerdo que en 1969, en el Congreso de la Sociedad Interamericana de Psicología que se realizó en Buenos Aires, escuché al psiquiatra peruano Alberto Seguín augurar las ideas de una disciplina centrada en la salud, con la clarividencia de un profeta, diciendo que la ciencia del futuro debería ocuparse no de lo peor del hombre sino de lo mejor, que en lugar de "psiquiatría" debería llamarse antropoiésis o algo por el estilo, poniendo el énfasis en el desarrollo y la perfección. Ahora, casi cuarenta años después, el vaticinio de Seguín está cumpliéndose con la Psicología Positiva, que superando el modelo de la enfermedad y de la reparación, propone un nuevo "modelo centrado en el fortalecimiento" (García, 2003), valorando las virtudes del carácter.

A continuación, describimos cada una de las fortalezas que la Psicología Positiva propone como inventario de los principios de vida que construyen el bienestar humano, las fortalezas del carácter que definen el concepto moderno de la salud o la calidad de vida. Se han distinguido 24 fortalezas que se agrupan en 6 grupos o dimensiones, que son las virtudes. Ellas son (Seligman, 2003; Peterson et al. 2004):

1. Sabiduría y conocimiento. Incluyen las fortalezas cognitivas que implican la adquisición y el uso del conocimiento.
(1) Curiosidad, interés por el mundo

Tener interés por lo que sucede en el mundo, encontrar temas fascinantes, explorar y descubrir nuevas cosas.

(2) Amor por el conocimiento y el aprendizaje Llegar a dominar nuevas materias y conocimientos, tendencia continua a adquirir nuevos aprendizajes.

(3) Pensamiento crítico, mentalidad abierta, capacidad de juicio

Pensar sobre las cosas y examinar todos sus significados y matices. No sacar conclusiones al azar, sino tras evaluar cada posibilidad. Estar dispuesto a cambiar las propias ideas en base a la evidencia.

(4) Creatividad, originalidad, inventiva, inteligencia práctica

Pensar en nuevos y productivos caminos y formas de hacer las cosas. Incluye la creación artística pero no se limita exclusivamente a ella.

(5) Perspectiva

Ser capaz de dar consejos sabios y adecuados a los demás, encontrando caminos no sólo para comprender el mundo sino para ayudar a los demás a comprenderlo.

2. Coraje. Es la virtud de las fortalezas emocionales que implican la consecución de metas ante situaciones de dificultad externa o interna.

(6) Valentía

No dejarse intimidar ante la amenaza, el cambio, la dificultad o el dolor. Ser capaz de defender una postura que uno cree correcta aunque exista una fuerte oposición por parte de los demás, actuar según las propias convicciones aunque eso suponga ser criticado. Incluye la fuerza física, pero no se limita a eso.

(7) Perseverancia y diligencia Terminar lo que uno empieza. Persistir en una actividad aunque existan obstáculos. Obtener satisfacción por las tareas emprendidas y que consiguen finalizarse con éxito.

(8) Integridad, honestidad, autenticidad Ir siempre con la verdad por delante, no ser pretencioso y asumir la responsabilidad de los propios sentimientos y acciones emprendidas.

(9) Vitalidad y pasión por las cosas 
Afrontar la vida con entusiasmo y energía. Hacer las cosas con convicción y dando todo de uno mismo. Vivir la vida como una apasionante aventura, sintiéndose vivo y activo.

3. Humanidad. Comprende las fortalezas interpersonales que implican cuidar y ofrecer amistad y cariño a los demás.

(10) Amor, apego, capacidad de amar y ser amado Tener importantes y valiosas relaciones con otras personas, en particular con aquellas en las que el afecto y el cuidado son mutuos. Sentirse cerca y apegado a otras personas.

(11) Simpatía, amabilidad, generosidad Hacer favores y buenas acciones a los demás, ayudar y cuidar a otras personas.

(12) Inteligencia emocional, personal y social Ser consciente de las emociones y sentimientos tanto de uno mismo como de los demás, saber como comportarse en las diferentes situaciones sociales, saber qué cosas son importantes para otras personas, tener empatía.

4. Justicia. Trata de las fortalezas cívicas que conllevan una vida en comunidad saludable.

(13) Ciudadanía, civismo, lealtad, trabajo en equipo

Trabajar bien dentro de un equipo o grupo de personas, ser fiel al grupo y sentirse parte de él.

(14) Sentido de la justicia, equidad

Tratar a todas las personas como iguales, en consonancia con las nociones de equidad y justicia. No dejar que los sentimientos personales influyan en decisiones sobre los otros, dando a todo el mundo las mismas oportunidades.

(15) Liderazgo

Animar al grupo del que uno es miembro para hacer cosas, así como reforzar las relaciones entre las personas de dicho grupo. Organizar actividades grupales y llevarlas a buen término.

5. Moderación. Abarca las fortalezas que nos protegen contra los excesos.
(16) Capacidad de perdonar, misericordia

Capacidad de perdonar a aquellas personas que han actuado mal, dándoles una segunda oportunidad, no siendo vengativo ni rencoroso.

(17) Modestia, humildad

Dejar que sean los demás los que hablen de uno mismo, no buscar ser el centro de atención y no creerse más especial que los demás.

(18) Prudencia, discreción, cautela

Ser cauteloso a la hora de tomar decisiones, no asumiendo riesgos innecesarios ni diciendo o haciendo nada de lo que después uno se pueda arrepentir.

(19) Autocontrol, autoequilibrio

Tener capacidad para equilibrar los propios sentimientos y acciones. Tener disciplina y control sobre los impulsos y emociones.

6. Trascendencia. Se refiere a las fortalezas que forjan conexiones con la inmensidad del universo y proveen de significado la vida.

(20) Apreciación de la belleza y la excelencia, capacidad de asombro

Saber apreciar la belleza de las cosas, del día a día, o interesarse por aspectos de la vida como la naturaleza, el arte, la ciencia.

(21) Gratitud

Ser consciente y agradecer las cosas buenas que a uno le pasan. Saber dar las gracias.

(22) Esperanza, optimismo, proyección hacia el futuro

Esperar lo mejor para el futuro y trabajar para conseguirlo. Creer que un buen futuro es algo que está en nuestras manos conseguir.

(23) Sentido del humor

Gustar de reír y gastar bromas, sonreír con frecuencia, ver el lado positivo de la vida.

(24) Espiritualidad, fe, sentido religioso

Pensar que existe un propósito o un significado universal en las cosas que ocurren en el mundo y en la propia existencia. Creer que existe algo superior que da forma y determina nuestra conducta y nos protege.

Como puede observarse la esperanza (No.22) constituye una fortaleza, integrada a la virtud de la trascen- 
dencia. Es de destacar que estas definiciones que constituyen los valores superiores del carácter han sido evaluadas y validadas, en cuarenta países diferentes del mundo, con resultados altamente satisfactorios, según los últimos informes (Seligman et al., 2005). Asimismo, la esperanza es considerada una emoción y un pensamiento positivo relacionado con el futuro -junto con el optimismo, la fe y la confianza-, que constituye un componente esencial en el constructo de la felicidad humana (Pereyra et al., 2005), como lo entiende muy bien, entre otros, Abdel-Khalek, de la Universidad de Kuwait (2006), al incluirla entre los criterios para realizar la evaluación de la felicidad.

\section{REFERENCIAS}

Abdel-Khalek A.M. (2006). Measuring Happiness UIT a Single-Item Scale. Social Behavior and Personality, 34(2), 139-150.

Abram H.S. y Gill B.F. (1961). Predictions of postoperative psychiatric complications. New England Journal of Medicine, 265 (1), 123.

Abramson L.Y., Metalsky G.I. y Alloy L.B. (1989). Hopelessness Depression: A Theory-Based Subtype of Depression. Psychological Review, 96 (12), 358-372.

Adamson J.D. y Schmale A.H. (1965). Object Loss, Giving Up, and the Onset of Psychiatric Disease. Psychosomatic Medicine, 7, 557-576.

Alloy L.B. y Ahrens A.H. (1987). Depression and Pessimism for the Future: Biased Use of Statistically Relevant Information in Predictions for Self Versus Others. Journal of Personality and Social Psychology, 52 (12), 366-378.

Alvord M.K. y Grados J.J. (2005). Enhancing Resilience in Children. A Proactive Approach. Professional Psychology: Research and Practice, 36 (3), 238-245.

Amlund Hagen, K., Myers B. J. y Mackintosh V.H. (2005). Hope, Social Support, and Behavioral Problems in At-Risk Children. American Journal of Orthopsychiatry, 75 (2), April, 211-219.

Anda R., Williamson D., Jones D., Macera C., Eaker E., Glassman A. y Marks J. (1993). Depressed affect, hopelessness, and the risk of ischemic heart disease in a cohort of U.S. adults. Epidemiology, 4: 285-294.

Baron R.S., Cutrona C.E., Hicklin D., Russell D.W. y Lubaroff D.M. (1990). Social Support and Immune Function Among Spouses of Cancer Patients. Journal of Personality and Social Psychology, 59 (12), 344-352.

Beck A.T. (1963). Thinking and depression. Archives of General Psychiatry, 9, 324-333.

Beck A.T. (1967). Depression: Clinical, Experimental, and Theoretical Aspects. New York: Harper \& Row.

Beck A.T., Steer R.A. y McElroy M.G. (1985). Hopelessness and eventual suicide: A 10-year prospective study of patients hospitalized with ideation. American Journal of Psychiatry, 142, 559-563.

Benzein, E.G. y Berg, A.C. (2005). The level of and relation between hope, hopelessness and fatigue in patients and family members in palliative care. Palliaive Medicine, 19: 234-240.

Bloch E. (1980). El Principio Esperanza. 3 tomos. Madrid: Editorial Aguilar.

Brackney B.E. \& Westman A.S. (1992). Relationships among hope, psychosocial development, and locus of control. Psychological Reports, Jun, 70 (3, Pt1), 864-866.

Brennan F.X. y Charnetski C.J. (2000). Explanatory Style and Immunoglobulin A (IgA). Integrative Physiological and Behavioral Science, Oct-Dec, 35 (4), 251-255.

Carson V.B., Soeken K.L., Shanty J. \& Terry L. (1990). Hope and spiritual well-being: Essentials for living with AIDS. Perspectives in Psychiatric Care, 26 (2), 28-34.

Carver C.S. y Gaines J.G. (1987). Optimism, pessimism, and postpartum depression. Cognitive Therapy and Research, Ago, 11 (4), 449-462.

Cassells C., Paterson B., Dowding D. y Morrison R. (2005). Long-and Short-Term Risk Factors in the Prediction of Inpatient Suicide: A Review of the Literature. Crisis, 26 (2): 53-63. 
Cousins N. (1981). La voluntad de curarse, el punto de vista del paciente. Buenos Aires: Emecé.

Crisp A.H. y McQueen M. (1984). Infarto de miocardio y estado emocional. The Lancet (ed.esp.), 5 (1), 65-68.

Cutrona, C.E. (1982). Nonpsychotic postpartum depression: A review of recent research. Clinical Psychology Review, 2, 487-503.

Deutsch H. (1942). Some psychoanalytic observations in surgery. Psychosomatic Medicine, 4, 105.

Drake R.E. \& Cotton P.G. (1986). Depression, hopelessness and suicide in chronic schizophrenia. British Journal of Psychiatry, May, 148, 554-559.

Ebert S.A., Tucker D.C. y Roth D.L. (2002). Psychological resistance factors as predictors of general health status and physical symptom reporting. Psychology, Health \& Medicine, 7 (3), 363-375.

Laín Entralgo P. (1957). La Espera y la Esperanza. Historia y Teoría del Esperar Humano. Madrid: Revista de Occidente.

Laín Entralgo P. (1978). Antropología de la esperanza. Barcelona: Guadarrama,

Esqueda Torres L. (1993). Cambios motivacionales post-infarto. Trabajo presentado en el Congreso Interamericano de Psicología, Santiago de Chile, 457-462.

Everson, S. A., Goldberg, D. E., Kaplan, G. A., Cohen, R. D., Pukkala, E., et al. (1996). Hopelessness and risk of mortality and incidence of myocardial infarction and cancer. Psychosomatic Medicine, 58, 113-121.

Fawcett J., Scheftner W., Clark D., Hedeker D., Gibbons R. y Coryell W. (1987). Clinical Predictors of Suicide in Patients With Major Affective Disorders. A Controlled Prospective Study. American Journal of Psychiatry, 144 (1), jan, 35-40.

Fitzgerald R. (1979). The sources of hope. Rushcutters Bay: Pergamno Press.

Gallo 1:C. y Matthews K. (2003). Understanding the association between socioeconomic status and physical health: Do negative emotions play a role? Psychological Bulletin, 129, 10-51.
García Averasturi L. (2003). La Psicología Positiva: del modelo de la reparación al modelo del fortalecimiento. Hojas Informativas de los psicólogos de Las Palmas, No. 56, Época II.

Given CH.W., Stommel M., Given B., Osuch J., Kurtz M.E. y Kurtz J.C. (1993). The Influence of Cancer Patients' Symptoms and Functional States on Patients' Depression and Family Caregivers' Reaction and Depression. Health Psychology, 12 (14), 277-285.

Goodkin K., Antoni M.H.\& Blaney P.H. (1986). Stress and hopelessness in the promotion of cervical intraepithelial neoplasia to invasive sgruamous cell carcinoma of the cervix. Journal of Psychosomatic Research, 30 (1), 67-76.

Haatainen K.M., Tnskanen A., Kylma J., Honkalampi K., Koivumaa-Honkanen H., Hintikka J., Antikainen R. y Viinamäki H. (2003). Gender differences in the association of adult hopelessness with adverse childhood experiences. Social Psychiatry and Psychiatric Epidemiology, 38 (1), 12-17.

Hall J.G. (1985). Emotion and immunity. Lancet, 2, 326-327.

Henker F. O. (1985). Hope and Recovery from surgical illness. Comprehensive Therapy, 11(11), 11-15.

Henry P.C. (2005). Life Stresses, Explanatory Style, Hopelessness, and Occupational Class. International Journal of Stress Management, 12 (3), 241-256.

Hickey S.S. (1989). Hope as a Key Element in Cancer Survivorship. Journal of Psychosocial Oncology, 7 (4), 111-118.

Holly P., Kennedy P., Taylor A. y Beedie A. (2003). Immediate breast reconstruction and psychological adjustment in women who have undergone surgery for breast cancer: a preliminary study. Psychology, Health \& Medicine, 8 (4), November, 441-452.

Itzhaky H. y Lipschitz-Elhawi R. (2004). Hope as a strategy in supervising social workers of terminally ill patients. Health \& Social Work, 29 (1), 46-54.

Jensen M.R. (1987). Psychobiological Factors Predicting the Course of Breast Cancer. Journal of Personality, 55 (2), June, 317-342. 
Kashani J.H., Dandoy A.C. y Reid J.C. (1992). Hopelessness in children and adolescents: An overview. Acta Paedopsychiatrica International Journal of Child and Adolescent Psychiatry, 55(1), 33-39.

Keinan G., Carmil D. y Rieck M. (1991-92). Predicting women's delay in seeking medical care after discovery of a lump in the breast: The role of personality and behavior patterns. Behavioral Medicine, Win, 17(4), 177-183.

Kim C.H., Jayathilake K. y Meltzer H.Y. (2003). Hopelessness, neurocognitive function, and insight in schizophrenia: Relationship to suicidal behaviour. Schizophrenia Research, 60, 71-80.

Kimball C.P. (1969). Psychological responses to the experience of open-heart surgery. American Journal of Psychiatry, 126, 348.

Kivimäki M., Vahtera J., Elovainio M., Helenius H., Singh-Manoux A. y Pentti J. (2005). Optimism and Pessimism as Predictors of Change in Health After Death or Onset of Severe Illness in Family. Health Psychology, 24 (4), 413-421.

Koivumaa-Honkanen, H., Honkanen, R., Viinama“ki, H., Heikkila“, K., Kaprio, J., \& Koskenvuo, M. (2001). Life satisfaction and suicide: A 20-year follow-up study. American Journal of Psychiatry, 158, 433-439.

Kylma J. (2005). Dynamics of hope in adults living with HIV/AIDS: a substantive theory. Journal of Advanced Nursing, Dec, 52 (6), 620-630.

Lancastle D. y Boivin J. (2005). Dispositional Optimism, Trait Anxiety, and Doping: Unique or Shared Effects on Biological Response to Fertility Treatment? Health Psychology, 24 (2), 171-178.

Leedham B., Meyerowitz B.E., Muirhead J. y Frist W.H. (1995). Positive Expectations Predict Health After Heart Transplantation. Health Psychology, 14 (1), 74-79.

Lin, H-R. y Bauer-Wu, S.M. (2003). Psycho-spiritual well-being in patients with advanced cancer: an integrative review of the literature. Journal of Advanced Nursing, 44(1), 69-80.

Lobel, M., DeVincet C.J., Kaminer A. y Meyer B.A. (2000). The impact of prenatal maternal stress and optimistic disposition on birth outcomes in medically high-risk women. Health Psychology, 19, 544-553.

Manley R.S. y Leichner P. (2003). Anguish and Despair in Adolescents with Eating Disorders. Helping to Manage Suicidal Ideation and Impulses. Crisis, 24 (1), 32-36.

McCranie E.W. y Riley W.T. (1992). Hopelessness and persistence of depression in an inpatient sample. Cognitive Therapy and Research, Dec, 16 (6), 699708.

Metalsky G.I. y Joiner T.E. (1992). Vulnerability to Depressive Symptomatology: A Prospective Test of the Diathesis-Stress and Causal Mediation Components of the Hopelessness Theory of Depression. Journal of Personality and Social Psychology, 63 (14), 667-675.

Moore, S. L. (2005). Hope makes a difference. Journal of Psychiatric and Mental Health Nursing, 12, 100105.

Nowotny M.L. (1989). Assessment of Hope in Patients With Cancer: Development of an Instrument. Oncology Nursing Forum, 16 (11), 57-61.

Nurmi J.-E. y Pulliainen H. (1991). The changing parent-child relationship, self-esteem, and intelligence as determinants of orientation to the future during early adolescence. Journal of Adolescence, Mar, 14 (1), 35-51.

Obayuwana A.O., Collins J.L., Carter A.L., Rao M.S., Mathura C.C. y Wilson S.B. (1982). Hope Index Scale: an instrument for the objective assessment of hope. Journal of the National Medical Association, 74 (18), 761-765.

Obayuwana A.O., Carter A.L. y Barnett R.M. (1984). Psychosocial Distress and Pregnancy Outcome: a three-year prospective study. Journal of Psychosomatic Obstetrics and Gynaecology, 3, 3/ 4, Dec, 173-181.

Marcel G. (1954). Prolegómenos para una Metafísica de la Esperanza. Buenos Aires: Ediciones Nova.

Papakostas G.I., Petersen T., Pava J., Masson E., Worthington J.J., Alpert J.E., Fava M. y Nierenberg A.A. (2005). Hopelessness and Suicidal Ideation in Outpatients With Treatment-Resistant 
Depression: Prevalence and Impact on Treatment Outcome. Focus 3, 140-145.

Pereyra M. (1995). La esperanza-desesperanza como variables diagnóstica y predictiva del proceso salud-enfermedad. Tesis doctoral, Universidad Católica de Córdoba, Córdoba, Argentina.

Pereyra M. (1997). Psicología de la esperanza con aplicaciones a la práctica clínica. Buenos Aires: Psicoteca editorial.

Pereyra M. y Mussi C. (2005). ¡Sea feliz! Cómo vencer la depresión y controlar la ansiedad. México: Publicaciones Universidad de Montemorelos, Montemorelos.

Peterson W. (1961). The art of Living: Thoughts on Meeting the Challenge of Life. New York: Galahad Books.

Peterson C. y Seligman M.E.P. (2004). Character, Strengths and Virtues. A Handbook and Classification. New York: Oxford University Press.

Rabkin J.G., Williams J.B.W., Neugebauer R., Remien R.H. y Goetz R. (1990). Maintenance of Hope in HIV-Spectrum Homosexual Men. American Journal of Psychiatry, 147 (10), Oct, 1322-1326.

Reff R.C., Kwon P. y Campbell D.G. (2005). Dysphoric responses to a naturalistic stressor: Interactive effects of hope and defense style. Journal of Social and Clinical Psychology, 24 (5), 638-648.

Roe D. y Chopra M. (2003). Beyond Doping UIT Mental Illness: Toward Personal Growth. American Journal of Orthopsychiatry, 73 (3), 334-344.

Rogers M.E., Hansen N.B., Levy B.C., Tate D.C. y Sikkema K.J. (2005). Optimism and Coping with loss in Bereaved HIV-Infected Men and Women. Journal of Social and Clinical Psychology, 24 (3), 341-360.

Rugulies R. (2002). Depresión as a predictor for coronary heart disease. A review and meta-analysis. American Journal of Preventive Medicine, 23, 5161.

Sábato E. (1985). Sobre héroes y tumbas. Barcelona: Seix Barral.

Sapolsky R.M.(1990). El estrés en los animales. Investigación y Ciencia, Mar, 68-75.
Schmale A.H. y Iker H.P. (1966). The Affect of Hopelessness and the Development of Cancer. I. Identification of Uterine Cervical Cancer in Women with Atypical Cytology. Psychosomatic Medicine, 28 (15), 714-721.

Schmale A.H. y Engel G.L. (1967). The Given upGiven up Complex. Illustrated on Film. Archives of General Psychiatry, 17, Aug.

Schmale A.H. y al. (1971). Hopelessness as a predictor of cervical cancer. Soc.Sci.Med., 5, 95-100.

Segerstrom S y Miller G. (2004). Psychological Stress and the Human Immune System: A Meta-Analytic Study of 30 Years of Inquiry. Psychological Bulletin. 130(4), Jul, 601-630.

Segerstrom S. (2005). Optimism and immunuty: Do positive thoughts always lead to positive effects? Brain, Behavior, and Immunity, 19 (3) May, 195200.

Seligman M.E.P. (2003). La auténtica felicidad. La nueva Psicología Positiva revoluciona el concepto de felicidad y señala el camino para conseguirla. Buenos Aires: Javier Vergara

Seligman M.E.P., Oteen T.A., Park N. y Peterson C. (2005). Positive Psychology Progress. Empirical Validation of Interventions. American Psychologist, 60(5), 410-421.

Shorey H.S., Snyder C.R., Rand K.L., Hockemeyer J.R. y Feldman D.B. (2002). Somewhere Over the Rainbow: Hope Theory Ewathers Its First Decade. Psychological Inquiry, 13 (4), 322-3310.

Simmons B.L., Nelson D.L. y Campbell Quick J. (2003). Health for the Hopeful: A Study of Attachment Behavior in Home Health Care Nurses. International Journal of Stress Management, 10 (4), 361-375.

Smith E. (1989). Aids and Personality. Psychology Today, 74. March,

Snyder C.R., Shorey H.S., Cheavens J., Pulvers K.M., Adams III V.H. y Wiklund C. (2002). Hope and Academic Success in College. Journal of Educational Psychology, 94(4), Dec. 820-826.

Srikumar A., Campbell D., Ruskin P. y Hebel R. (2000). Depression, Hopelessness, and the Desire for Life- 
Saving Treatments Among Elderly Medically Ill Veterans. American Journal Geriatric Psychiatry, 8(4), Fall, 333-342.

Stern S.L., Dhanda R. y Hazuda H.P. (2001). Hopelessness Predicts Mortality in Older Mexican and European Americans. Psychosomatic Medicine, 63, 344-351.

Suls J. y Bunde J. (2005). Anger, Anxiety, and Depression as Risk Factors for Cardiovascular Disease: The Problems and Implications of Overlapping Affective Dispositions. Psychological Bulletin, 131(2), 206-300.

Tiger L. (1979). Optimism: The biology of hope. New York: Simon \& Shuster.

Tomakowsky J., Lumley M.A., Markowitz N. y Frank C. (2001). Optimistic explanatory style and dispositional optimism in HIV-infected men. Journal of Psychosomatic Research, 51(4), Oct, 577-587.

Udelman D.L. (1982). Stress and Immunity. Psychotherapy and Psychosomatic, 37, 176-184.

Viñas Poch F., Villar E., Caparros B., Juan J., Cornella M. y Perez I. (2004). Feeling of hopelessness in a Spanish university population. Descriptive análisis and its relationship to adapting to university, depressive symptomatology and suicidal ideation. Social Psychiatry and Psychiatric Epidemiology, 39(4), 326-334.

Zwanck G. (1980). Higiene del alma. El día médico, Bs.As., 52, 379.

Fecha de recepción: 15 de enero, 2010

Fecha de aceptación: 20 de febrero, 2010 